\title{
The Geospatial Rhetoric of Asylum: Mapping Migration in Fortress Europe
}

\author{
JOSHUA SYNENKO, Trent University
}

\begin{abstract}
In July 2015, a German neo-fascist group published a Google Maps page containing georeferenced information of the country's known asylum houses, bearing the title of 'no refugee centre in my backyard'. This article examines how the group's information gathering tactics are reflected by long contested relationships between maps, power and the construction of identity. In an effort to expose the narratives, subjects and futures that are galvanized by geospatial imaging and the extremist group's Google Maps campaign in particular, the article ultimately questions whether it is viable to redirect the growing antipathy for Europe's new migrant population by appealing to spatial demands that are historically aligned with social justice. In the process of answering this question, the article expands upon selected methodological, historical and theoretical problems. These include: the epistemic assumptions behind rejecting politically motivated maps as propaganda; the logistical or strategic novelties associated with crowdsourcing information; and the narrative power of maps, with an emphasis on the specific narrative practices associated with geospatial technologies.
\end{abstract}

\section{KEYWORDS}

European migrant crisis, GIS, Google Maps, Interfaces, Neo-fascism

\section{Introduction}

The year 2015 marked a tipping point in the European migrant crisis, as hundreds of thousands displaced from conflicts in Syria and other parts of the Middle East entered European jurisdictions seeking asylum. Though the crisis itself started months earlier, the debate about whether European leaders had a particular responsibility for absorbing this population arrived rather late in the game with the circulation of an image featuring Alan Kurdi, a boy lying dead on a Turkish beach. Prior to that image, a small but vocal minority united in antipathy for the incoming migrants took to the Internet to express their views. In July, an online Google Map containing geo-referenced information of Germany's known asylum houses appeared with the title of 'no refugee centre in my backyard'. Authored by Der III Weg, a neo-fascist group with operations extending from Germany's southwest region, the map was developed in part as a crowdsourcing initiative to provide real time updates regarding the status of asylum infrastructure developments, complete with details about the number of spaces available for occupancy. Though the map was quickly taken down following user complaints, it resurfaced the following day together with a statement issued by 
the group: 'We affirm the fundamental right to asylum, but refuse asylum abuse categorically'. Today, the map is presented on Der III Weg's website primarily as a logistical and strategic tool, though it has also been used in various promotions and recruitment drives. In its first iteration, the map gained traction by appearing on local and state news, notably the German television service Tagesschau. More recently, Der III Weg has been connected to arson attacks on houses where migrants are located, ${ }^{1}$ and, while positively establishing such connections are rare, it is likely the map has contributed to the fivefold increase of attacks on asylum houses in 2015 compared to the previous year (Hill 2016).

Beyond public statements of denial by the group's spokespeople, Der III Weg's decision to represent the migrant crisis with a cartographic image harbours specific assumptions about the validity of a migrant's appeal for asylum. Further to this, however, despite the accuracy and precision that GIS technology displays in identifying Germany's asylum houses within a familiar topography, the map does not directly communicate the group's desired aims and therefore avoids any culpability for the attacks that it may provoke. Nevertheless, by utilizing the geo-referenced markers of Google Maps without any corresponding directives or prompts for action, the implied suggestion appears to be that such decisions must be left to the individuals themselves. The map thus establishes a circuit of information transfer that both begins and ends with individual sympathizers of the party's basic message. In other words, while the construction of the map is entirely dependent upon information provided by its viewers, its ultimate purpose is that of promoting acts of vigilante violence among the very same demographic. This feedback loop is effectively mobilized by a cartographic prompt that stands at a threshold between simultaneously revealing and obscuring the associations of collective identity and solidarity that are shared by the map's contributors. On the basis of this double gesture, then, further questions should be raised as to how Der III Weg's campaign benefits from the power of cartographic imaging, and indeed whether it is productive to situate its effects and practices within a critical literature that has long explored the relationships between maps, power and identity.

This article considers such questions with an air of foreknowledge about the cultural assumptions that propel Der III Weg's engagement with geospatial technology. In particular, the simulated content of the group's mapping campaign invites us to question how georeferenced images have redirected the pathways of collective identity in a time of Fortress Europe, which in this case refers to a sense of collective anxiety regarding the geographical integrity of the region at large. What, on this basis, are the specific narratives, subjects and futures that Der III Weg draws from during the process of constructing such imaginaries? And is it possible to redirect these imaginaries by appealing to spatial demands that are historically aligned with social justice action? In the hopes of revealing some of the dynamics between European politics and geospatial data imaging, this article will address these questions by investigating three areas of contested inquiry. First, by revisiting the critical discourse on human geography in relation to a history of space, I isolate specific challenges to the categorical rejection of so-called 'propaganda' maps, arguing that by rejecting such imagery we fail to address the more significant task of undermining claims that are associated with

\footnotetext{
${ }^{1}$ https://www.tagesschau.de/inland/der-dritte-weg-103.html
} 
cartographic objectivity (Harley 1989; Pickles 2003). Second, by turning to a wider set of post-representational mapping practices, I analyze Der III Weg's capacity of using Google Maps to advance logistical or strategic aims, and, as an extension of this analysis, I compare the group's application of the GIS interface with documentary images that are present throughout their social media archive (Drucker 2014; Parks 2009). Third, by extending Sébastian Caquard's discussion of 'the narrative power of the map' (2014), I examine Der III Weg's campaign in relation to a mode of constructing cartographic imagery as an index of 'play' (Kingsbury 2009; Galloway 2014). I conclude with a brief speculation about whether mapping practices by extremist groups in Europe can in fact be supplemented by spatial demands for inclusive social justice action (Harvey 2009; Soja 2010).

\section{Deconstructing Cartography in a Time of European Extremism}

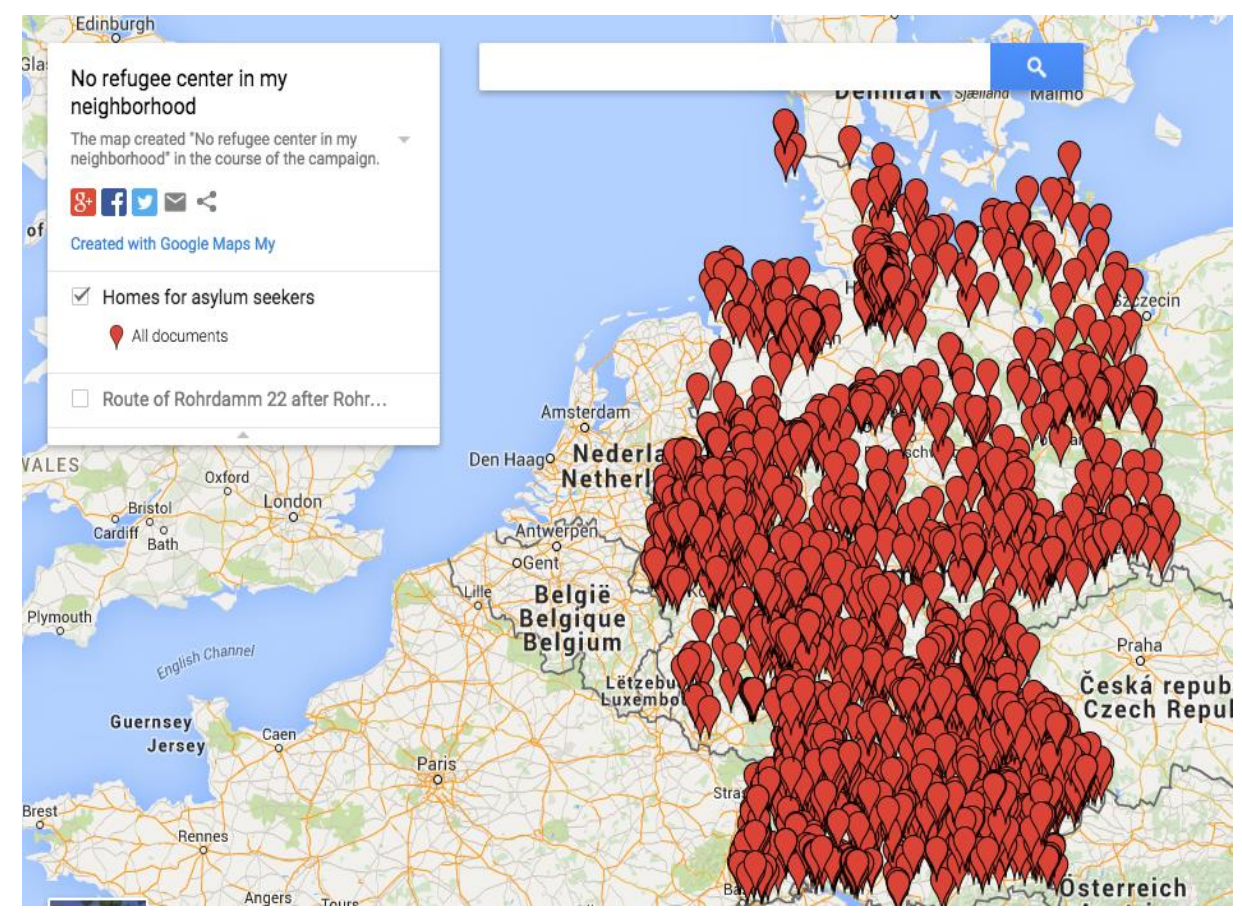

Fig. 1 Screen capture of Der III Weg's Google Maps, "No refugee center in my neighbourhood" (Map Data@ 2015 Google)

Like PEGIDA or Chrysí Avgí, the Der III Weg group is a regionally active neo-fascist party with an ambitious mandate to expand their operations, particularly in the hopes of developing an extremist network united by revolutionary aims. Above all, this slowly emerging network of actors appears to have achieved consensus in their commitment to promoting antiimmigration policies on the public stage, and to advocating for violence as a solution to the migrant crisis. In light of recent events associated with the changing European political landscape, commentators like Slavoj Žižek (2012) and Franco Berardi (2015) have suggested that the return to extremist positions within the mainstream has blurred the traditional boundaries of the political spectrum. I argue, however, that while idiosyncrasies undoubtedly 
exist within extremist organizations, the categorical rejection of new immigration policy has united everyone who may be affiliated with the European far right. Der III Weg, for instance, has in the past expressed a number of counter-intuitive allegiances to anti-imperialism as connected to the Palestinian cause. Indeed, it may be the case that Der III Weg's antiimperialist bias stems from their emotional debt to the Nazi Party of the Third Reich, which materializes in their support for a wholly anachronistic vision of the German Volk - a vision that the group routinely characterizes as imperiled by global Zionist conspiracy. With repeated references on their website to anti-Semitic statements by philosophers such as Arthur Schopenhauer, Friedrich Nietzsche and Richard Wagner, it is plausible to suggest that Jewishness and Zionism are understood by the group to be identical. Aside from these obscurities in the group's core beliefs, therefore, I argue that Der III Weg is a microcosm of the new extremism that has recently swept the entire region. From this perspective, the Google Maps image of Germany's asylum houses not only substantiates Der III Weg's efforts at forging broader solidarities with like-minded others, but it also re-simplifies their message by returning to policy commitments with broad appeal.

Alongside its logistical or strategic applications, I argue that the Google Maps image of the asylum houses accurately represents an existential threat for any extremist position, and indeed the content of the map has been characterized in this way to promote connections with individuals and organizations from afar. In other words, by partially assuming an iconic function, the Google Maps image undoubtedly has considerable value as propaganda, as it carries the potential to become a signifier of the broader movement to eliminate migrants once and for all. Der III Weg in fact demonstrates the iconic significance of the map by parading the image across placards and message boards during street demonstrations, as well as by copying the map on information pamphlets, not to mention the cover page of their website. By isolating this iconic function of the map, I hereby extend my analysis to a critical discourse surrounding the application of cartographic images as propaganda. More specifically, there is a sense from critical geographers that dismissing such maps on the basis of their inherent bias is to miss a significant point regarding the power of cartographic imaging - even if the map so depicted does not exemplify its logistical or strategic use-value in every given circumstance. John Pickles, for one, has given considerable attention to the tendency of regarding politically motivated representations as some kind of deviance, or 'distortion,' of the map's established authority as a material instantiation of irrefutable truth $(2004,37)$. Pickles rehearses the arguments of established works in which direct challenges are made to the apparent misuse of maps by politically motivated actors. Noting, for instance, that 'the geographical imagination is one that is historically and personally identified with the cartographic image,' Pickles claims that all such images, whether they are deemed to be propagandistic or not, either contribute or become tethered to the legitimating thrust of a scientific cartographic practice $(2004,9)$.

As Pickles explains throughout his book, this practice derives from a causative relationship between the discipline of geography and the traditions of western thought - whether by appealing to science or the rhetoric of precision, or by the simple act of making visible. He argues that regardless of whether a map is deemed to be 'propagandistic', the very rejection of its content on the basis that it is designed to meet the aims of particular actors should be 
supplemented in turn by acknowledging the image's truth effects. Pickles writes that beyond instantiating truth, "cartographers manufacture power," and, by and large, that power is wielded by claims to truth that are validated with allusions to the verifiable coordinates that the map represents as visual content $(2004,12)$. This view is supported by references to John Brian Harley's canonical text, 'Deconstructing the Map' (1989), in which the author challenges the tendency for map makers to become invested in creating mirrors of nature, or otherwise to assume that their products reflect the truth claims that have been invested in traditional authorities. This question is especially important if we extend the conversation to the availability (and ubiquity) of digital map applications that coincided with the introduction of Web 2.0. Though access to GIS technology was slowly parceled out to mitigate the potential for danger that such availability might present for state and military actors (Kurgan 2013, 21), the discourse surrounding this technology according to Harley is mainly regressive because it harkens back to the objectivist assumptions within map-making in general. For Pickles, the introduction of the GIS map exemplifies the push towards 'democratizing information while representing specific interests' $(2004,13)$. In Der III Weg's case, it is these specific interests that serve to validate their enterprise from the start.

Considering, then, that if a key priority for analysis is to avoid characterizing power relations within maps as a 'distortion' of cartographic truth, accuracy or precision, perhaps Der III Weg's online activities could be better analyzed or critiqued as an expression of 'cartographic anxiety', a condition described by Derek Gregory (1994) as the result of attempting to participate in the power of the cartographic image through making direct appeals to its claims of objectivism, or at least, by playing on assumptions regarding such claims (73). As GIS increasingly dominates the field of map-making practices, and thereby blurs the traditional boundaries as to what truth and error signify, a new field of interpretation is slowly taking their hallowed place. Now more than ever, Pickles writes, 'mapping is an interpretive act, not a purely technical one'; in other words, 'the map is a text' in the sense that it attributes more than a single author, and therefore speaks to diverse interests, perspectives and levels of power (43). Despite sharing Harley's concern about the dynamics of power that lie beneath the representational authority of maps, Pickles further claims it is necessary for analysts to get beyond examining the cartographic text on the basis of how it "was wielded" by particular interests, to consider instead 'the map function itself' $(2004,65)$. In other words, by turning to David Wood's (1992) position in The Power of Maps, Pickles wants to assess the function of a given map through an investigation of its particular accomplishments. To determine how this question plays out in the example provided by Der III Weg's Google Maps initiative, a new set of questions need to be addressed surrounding the logistics of mapping intervention.

\section{The Logistics of Mapping Intervention}

There are but few precedents for Der III Weg's decision to use a digital mapping interface that exists in the public domain for the purposes of staging or enhancing violent interventions on the ground. One precedent of this activity is explored by Lisa Parks (2009) in her analysis of the 2007 partnership between the Google Corporation and the United States Holocaust Memorial Museum (USHMM), in a media-driven campaign that was aimed at bringing 
attention to the genocidal wars in Darfur. As Parks describes, this particular campaign was designed to raise awareness about an under-reported conflict with the express desire of preventing the continuation of genocidal violence, and ultimately to elicit help from the international community through popular demand. Despite these efforts, Parks critiques the USHMM for reviving problematic assertions embedded in colonial narratives, for preventing the transmission of facts on the ground, and for normalizing the efforts of 'disaster capitalism' (2009, 542). Accordingly, these otherwise valid critiques of the Darfur project do not apply as evenly to an analysis of Der III Weg's campaign, which uses the cartographic prompt in Google Maps Maker precisely to instigate the crimes of elimination as opposed to stopping them. Furthermore, the intended audience of the Darfur campaign is not the public per se, but rather an international community that has both the moral and political authority to go to war. The Der III Weg map, on the other hand, calls upon disenchanted individuals to become the perpetrators of violence in their own communities. Granted, Parks makes a significant point that we must continue 'to evaluate how representations of global conflicts are changing with uses of new information technologies' $(2009,535)$. However, by that very same token, I argue that Der III Weg's campaign raises a different set of questions in regard to the modes of subjectivity and the tactics of public engagement that are facilitated by these technologies.

Another example that may help to situate Der III Weg's campaign is the 2011 story from Libya during the first wave of its Civil War, in which it was reported that rebel forces used Google Earth and iPhone applications as part of their strategic efforts to locate enemy targets (Coghlan 2011). This story was unique at the time because it showed how rebel groups from any part of the world now have the means to gain logistical or strategic military advantage from the GPS coordinates that are abundantly available online. Moreover, the digital mapping initiatives used by Libyan rebels are significant in terms of their variance from the oftmentioned deployment of social media in revolutionary Egypt, in which commentators extolled the virtues of using corporate platforms like Facebook and Twitter on mobile devices to forge solidarities between disparate groups within Cairo, and, in turn, to contribute a sense of conviviality and participation that would then reverberate to other more vulnerable parts of the region. Though both examples reflect certain aspects of what is now taking place in Germany regarding the contestation over the status of migrants, one of the principal differences in the latter, particularly in comparison with the Google Maps campaign, is its dependency upon crowdsourcing information to generate reliable targets. On the one hand, while this dependency may reveal that the Der III Weg group is resource poor, or that it relies upon homespun techniques because it lacks technological resources, another interpretation may emphasize the resiliency and viability of extending the crowdsourcing initiative to the sphere of digitally mapped public space.

Indeed, this unique aspect of the Der III Weg campaign brings into focus the ethical stakes involved in transforming the universe of Google Maps through crowdsourcing initiatives - an effort that has been dramatically accelerated in recent years. Certainly, with applications like Google Maps Maker, the company is now in a strong position to make a direct appeal to receiving information from their users. For instance, on the opening page, the Maker encourages users 'to enrich Google Maps with your local knowledge'. This unabashed affirmation of the local brings to light a point made by Sébastian Caquard (2011) regarding 
the exploitative potential of applications like crowdsourcing for the digital mapping enterprise. Caquard writes, 'Google plays on the commitment to a democratic mapping vision in order to create a sense of belonging to a community that reciprocally stimulates the free participation of volunteers' $(2011,137)$. This value is expressed as well by Der III Weg with their insistence that the Google Maps targeting asylum houses is part of an effort to democratize the policy-making process in order to stop migrants from abusing the system. However, what is most fascinating and consequential in this affirmation of crowdsourcing is the way in which participation itself is changing the nature of what it means to belong to a community at all. Though the facilitation of crowdsourcing retains the democratizing function promised by Google, I argue that another set of questions should be explored in terms of Google's transformation of cultural significance accorded to the local.

To put it another way, Der III Weg's campaign to target migrants in digital space reveals that the larger social function of the crowdsourcing technology is hereby to vindicate and celebrate particular German collective identity formations and to discredit others. In this sense, the individuals who supply information to Der III Weg's map are the agents of German social transformation. It may therefore be necessary to examine how the digital map becomes a facilitator of specific narratives. For Sébastian Caquard and William Cartwright (2014), the crowdsourcing application that Google strongly encourages us to utilize has contributed to a paradigm shift in commonly held assumptions about the narrative functions that digital maps contain. Caquard and Cartwright explain that prior to the introduction of Web 2.0 and the saturation of GIS technologies over diverse web applications, the connection between maps and narratives was for a time exclusively associated with the practice of using cartographic supplements for pre-existing story formats; in other words, it was used to materialize 'the spatial structures of stories' $(2014,102)$. According to Caquard, these story maps belonged, and still belong to a representational paradigm because of the way such maps must be situated as visual and spatial reference points for a given story $(2011,135)$. In other words, story maps offer a touchstone for imaginaries of space precisely by serving to facilitate the visual perception of the audience or reader. With the onset of Web 2.0, on the other hand, the 'grid maps' that once provided such narratives with a template for their articulation have been 'hybridized' in such a fashion as to become generators of narrative in their own right (Caquard 2011, 135). 'Within the context of the geoweb, any internet user can log on to an online mapping platform and add her own narrative or data on top of a base map' (Caquard $2011,137)$. Indeed, it is through such facility that grid maps have eventually come to produce narrative structures that accord with their specific modes of operation, with the further implication that that these mapping practices have entered an era that is fully postrepresentational.

\section{The Narrative Interface}

Caquard and Cartwright thus emphasize "the power of maps to stimulate and support narrative processes" $(2014,104)$. In particular, the proliferation of "navigational" metaphors in the digital sphere is a notable symptom of the recent changes that cartographic applications have had to our perception of place. But the narrative potential that is offered by this 
'navigational platform' (Caquard 2011, 138) is highly contested by media scholars like Francesco Cassetti (2013). The navigational bias to which Caquard refers is imperiled according to Cassetti by the foreclosure of the cinematic screen, which he identifies as a locus for building narratives in which to support the affects of particular communities. Described in further detail with an oblique reference to Lev Manovich's (2000) insight on the transition from cinematic to digital screens, Cassetti argues that longstanding notions of cinematic experience have since been resoundingly displaced by screen metaphors that do not abide to the cinemas's narrative conventions. Cassetti highlights the way in which online screen cultures adopt 'figures that function as memoranda, as signposts and, above all, as instructions for behaviour' $(2013,24)$. The implications of adopting such figures are considerable, as without the coherent foundation of a cinematic world picture, its replacement by geospatial information would require becoming amnestic towards the various cinematic modes of identity, resistance, redemption and future. Following Vilém Flusser (1983), Cassetti observes that 'the image is no longer engendered by facts; rather, it is born of an amalgamation of elements that are concretized according to circumstances' (2013,31). In other words, given the diminishment of cinematic forms, the narrative structure that retains an advantage for Cassetti is the one that is culled from the obdurate demands that are made upon the users of the interface.

Whether we accept Caquard's affirmative stance towards the navigational platform of Web 2.0, or Cassetti's defensive return to the cinema in lieu of alternatives to the behavioural prompts of the digital screen, the mutual factors at issue here have become integral to the production of narratives and imaginaries within communities. For instance, in Der III Weg's social media accounts on Twitter and Facebook, the group has put together a substantial archive of images and stories that bear a conspicuous affinity with the geospatial content that is explored through their Google Maps campaign. Granted, this social media archive includes a diversity of material, from pictures taken at street demonstrations and rallies to closed-door meetings and private dinners, from pictures of rank-and-file members greeting sympathetic individuals elected to city councils, to members dressed as Santa distributing information pamphlets at winter markets. This cache of images presents the group in a positive light by satisfying the expectations of a sympathetic audience for representations of a legitimate political party or movement. Alongside this promotional content, however, there is another set of images that can only be described as operational. In these images, deliberate attempts are made to secure the anonymity of the figures appearing in the frame. Often, these images will show a man with his back faced towards the camera, with an outstretched hand clutching information pamphlets against a road sign. ${ }^{2}$ In other versions, the anonymous figure disappears from the frame to leave just a handful of pamphlets with the road sign appearing in the distance. In one unique instance, both the road sign and the pamphlet are exchanged for an all-encompassing figure overlooking valleys encompassed by mountainous terrain.

Certainly, evidence of geo-referenced material in Der III Weg's social media archive would appear to corroborate Caquard's suggestion regarding the significance of the navigational

\footnotetext{
${ }^{2}$ https://www.facebook.com/Der-III-Weg-269180729959265/photos_stream
} 
metaphor in producing narratives. However, this suggestion does not help to illuminate the ambiguous purpose that lies behind creating such images. It would be purely speculative, for example, to determine that such images reveal the group's obsession with spatiality. Perhaps a more plausible suggestion would be that these images serve as a means of communicating recruitment initiatives to disparate bases of the group. Whatever one chooses, these images clearly demonstrate their uniqueness in the fact that they deploy the signature of place to communicate a verifiable and yet unspecified danger. In fact, this deployment is identical to the locational markers that appear in the group's Google Maps design. There is, then, a framework of sorts for how the construction of simulated targets in mappable space bears resemblance to the photographs depicting anonymous members standing in front of municipal road signs. Lisa Parks adds to this conversation by analyzing the use of maps in conjunction with photographs in USHMM's Darfur campaign, which according to her revolved around a curatorial strategy of embedding photographs of atrocities into satellite views marking their precise geographical location. Parks expresses her ambivalence of this strategy, because, as she claims, it eclipses the specificity of the cartographic image 'in search of closer and presumably more meaningful perspectives' (2009, 538). Therefore as Parks forewarns, the strategy for using photographs is ultimately to compel viewers into accepting the West's declaration of authority over contested terrain $(2009,538)$. On this basis, while Der III Weg's location-specific photographs are not dialectically related to their Google Maps campaign as the Darfur images are to the digital maps of the region, I argue that it is still useful to consider this critique by Parks because it highlights how pictorial content bridges the gap between ideological and logistical or strategic functions.

\section{Play and the Subject}

Finally, further investigation is needed on the factor of play that becomes infused in the navigational design of the interface. In fact, the significance of play has been magnified by the unparalleled force of cultural impact that cartographic imaging has enjoyed in recent years. For instance, Paul Kingsbury (2009) has argued that with the vast expansion of Google's cartographic empire into popular domains, the resulting narratives and adaptations have become far too diverse for the standing assumption that geospatial technologies are linked exclusively to the coercive practices of state and military actors. For his part, Kingsbury argues for a Dionysian reading of techno-culture that is alternatively structured by the playful elements of fantasy, frenzy, paranoia and jubilation $(2009,503)$. These elements may be useful in previous assessments made above as to the scope and limitations of Der III Weg's particular incitement, which I suggest reveals a project of narrative production and not simply a paramilitary one. On the other hand, there is a sense in which the cultural value of play that Google's cartographic empire represents emerged from the seat of much broader epistemic changes. For Alexander Galloway (2014), the graphical interface is an effect of 'romanticocybernetic play,' which Galloway describes as a symptom of 'ludic capitalism,' that is, a social structure in which 'flexibility, play, creativity and immaterial labor...have taken over from the old concepts of discipline, hierarchy, bureaucracy and muscle' (27). If we then consider Der III Weg's playfulness in light of these wider epochal changes, the Google Maps targeting campaign might be regarded as dangerous not only because it provides information 
as to the whereabouts of future asylum claimants, but also because it expedites perilous modes of self-fashioning.

The obsession with play conjures up enough skepticism for Galloway to question whether it is indeed possible to devise a method of interpretation in which technical images can be successfully displaced from their foundations, or whether they need to be positioned in such a way that the very demand for playfulness is rendered obsolete. As Galloway insists, the effectiveness of interpretation depends on one's ability to address the interface on its own terms, which, as Galloway explains, can be achieved by putting aside the temptation to critique the ideologies of those who apply cartographic imaging to meet specific political or strategic aims. Above all, the critical task for Galloway is not 'to reenact the interface, still less to define it, but to identify the interface itself as historical' $(2014,30)$. However, by using the historical lens, Galloway must privilege those interpretations that describe the interface as a product or effect of relationships as opposed to an object. For example, if we examine Der III Weg's recruitment campaigns, it would be impossible for us to describe their georeferenced targets as a remediation of either the road signs or the anonymous campaigners that appear in the photographs. In this case, it might be much more useful to question the nature of the dialogue that occurs between these two distinct sets of visual content. For Galloway, the preferred approach would be to characterize such dialogue in terms of friction or agitation, and, in other words, to imagine or conceive of the interface as fertile or generative as opposed to merely facilitating (2014, 31). Indeed, this critical approach of Galloway's resonates with Caquard and Cartwright's insistence on digital cartographic imaging as post-representational $(2014,104)$.

Johanna Drucker (2014) echoes Galloway's remarks regarding the digital mapping interface as a site of tension and re-articulation. In other words, Drucker like Galloway cautions against dominant perceptions that the interface merely offers a portal into virtual space. By drawing from a history of interface design, Drucker observes that the construction of access to virtuality is always informed by cultural codes, particularly when it comes to the relationship between subjects and objects. In Windows, for example, the 'object-oriented' universe defines figures of agency by their capacity to gain access to information (Drucker 2014, 142). Presuming that the 'user' as such is a consumer of information in addition to being a producer, the interface will be conceived in turn as a value-neutral design to achieve the user's aim. Drucker, by contrast, maintains that 'the structure of an interface is information, not merely a means of access to it' $(2014,143)$. That is, by reasserting the agency of a humanistic 'subject' in which to challenge the predominance of user-oriented designs, Drucker returns to critical humanistic practices of interpretation that are favoured for their capacity to devise the core strategies for a critical engagement in the virtual sphere. She writes, 'interface is what we read and how we read combined through engagement' (Drucker 2014, 147). On this basis, I argue that Drucker's insistence that we nurture figures of subjectivity offers the potential for making a strong critique of Der III Weg's effort to operationalize Google Maps to continue its campaign of intimidation and violence. For Drucker, in other words, critical reading practices involve delving into virtual space and revealing its capacity for 'relational experience' (2014, 153). Above all, this value of 
experience is one that goes beyond being implied or consciously policed, to being rendered mutable, unstable and possible.

\section{Conclusion}

In fact, Drucker's attempt at bringing conversations of 'relational experience' to questions about the digital interface and its privileged modes of subjectivity is consistent in many ways with Edward Soja's (2010) return to humanistic demands for justice in response to the spatial transformations of contemporary society. Soja writes that subscribing to notions of justice requires relieving spatial thinking from its subordination by history, in other words, 'to rebalance the spatial, the social, and the historical dimensions of reality' $(2010,18)$. Doing so is essential here as well, as formulating a critique of Der III Weg's campaign would be impossible without recognizing the magnitude of spatial thinking in general, and the impact of such thinking upon their collective identity as a group. Second, a concrete manifestation of spatial justice requires a commitment to material actions that are aimed at the betterment of contemporary societies. Soja writes that 'since we construct our multiscalar geographies, or they are constructed for us by more powerful others, it follows that we can act to change or reconfigure them to increase the positive or decrease the negative effects' $(2010,19)$. As David Harvey (2009) adds, such appeals to justice are rooted in traditions of normative action (97). But perhaps these demands strike the reader as idealistic, particularly in light of neofascist campaigns in which the favoured means of spatializing German community proves impossible to challenge. Indeed, this felt impossibility derives from the fact that Der III Weg's narratives have been constructed somewhat directly from the technical apparatus that is mobilized to communicate their messages.

On the other hand, Soja's demand may be helpful in terms of proposing concrete actions for Parks' insistence that we begin acknowledging the impact of new technologies on our perception of global conflicts, and that we in turn develop a critique in which normative action becomes the goal. In fact, this insistence by Parks pairs with Laura Kurgan's (2013) forewarning that 'only through a certain intimacy with these technologies - an encounter with their opacities, their assumptions, their intended aims - can we begin to assess their full ethical and political stakes' (14). From this perspective, Der III Weg's campaign illustrates particularly well the tendency of digital cartographic imaging to promote a sense of what Kurgan refers to as the 'disorientation' that attends to the unhinging of our 'fixity' in space $(2013,15,26)$. This is particularly notable as modes of participation that are unique to geospatial technologies like crowdsourcing are instrumentalized by extremist groups in ways that simply contradict the normative limits of the powers that govern them. For instance, we can see this contradicting impulse in the case of Google's encouragement to galvanize local knowledge as a way of strengthening one's own community and sense of belonging in space. If cartographic images authored by neo-fascists are therefore to be brought into line with spatial demands that are historically aligned with social justice, we need perhaps to exploit the potential that is contained in the apparatus itself. What we need is to further disentangle the particular agencies and applications of the apparatus, and to do so despite the danger that it 
may bring to the communities that operate in such a fashion. We need, in short, to reimagine the local.

\section{References}

Berardi, F. (2015) Heroes: Mass Murder and Suicide, New York: Verso

Caquard (2011) 'Cartography I: Mapping narrative cartography', Progress in Human Geography, 37, 1, 135-144

Caquard, S. and Cartwright, W. (2014) 'Narrative Cartography: From Mapping Stories to the Narrative of Maps and Mapping', The Cartographic Journal, 51, 2, 101-106

Cassetti, F. (2013) 'What Is a Screen Nowadays?', in C. Berry, J. Harbord and R. Moore (eds), Public Space, Media Space, New York: Palgrave Macmillan, pp. 16-40

Coghlan, T. (2011) 'Google and a notebook: the weapons helping to beat Gaddafi in Libya' The Times, 16 June (online). Available at http://www.thetimes.co.uk/tto/news/world/middleeast/article3063425.ece

Drucker, J. (2014) Graphesis: Visual Forms of Knowledge Production, Cambridge and London: Harvard University Press

Flusser, V. (2000) Towards a Philosophy of Photography, London: Reaktion Books

Galloway, A. (2014) The Interface Effect, Cambridge: Polity Press

Gregory, D. (1994) Geographical Imaginations, Cambridge: Blackwell Publishers

Harley, J.B. (1989) 'Deconstructing the Map', Cartographica, 26, 2, 1-20

Harvey, D. (2009) Social Justice and the City (Revised Edition), Athens, GA/London: The University of Georgia Press.

Hill, J. (2016) 'Migrant attacks reveal dark side of Germany', BBC News (online). Available at http://www.bbc.co.uk/news/world-europe-35633318

Kingsbury, P. (2009) 'Walter Benjamin's Dionysian Adventures on Google Earth', Geoforum, 40, 502-513

Kurgan, K. (2013) Close Up at a Distance: Mapping, Technology \& Politics, New York: Zone Books

Manovich, L. (2001) The Language of New Media, Cambridge: MIT Press 
Parks, L. (2009) 'Digging into Google Earth: An Analysis of "Crisis in Darfur”' Geoforum, $40,535-545$

Pickles, John (2004) A History of Spaces: Cartographic Reason, Mapping and the Geo-Coded World, New York: Routledge

Soja, E. W. (2000) Seeking Spatial Justice, Minneapolis: University of Minnesota Press

Wood, D. (1992) The Power of Maps, New York: The Guilford Press

Žižek, S. (2012) 'What Does Europe Want? Beyond the Multiculturalist Deadlock', ABC Religion and Ethics (online). Available at http://www.abc.net.au/religion/articles/2012/07/24/3552623.htm

Dr. Joshua Synenko received his Ph.D in 2015 from York University (Canada). His dissertation is entitled After Collective Memory: Post-national Europe and Socially Engaged Art. Dr. Synenko has published articles on European collective memory, critical media arts practice, and visual communication. He is a sessional lecturer in the Department of Sociology at Trent University (Canada).

Email: josh.synenko@gmail.com 